\title{
Characterization of biofilm formation by clinical isolates of Mycobacterium avium
}

\author{
George Carter, ${ }^{1}$ Martin Wu, ${ }^{1,2}$ Daryl C. Drummond ${ }^{2}$ \\ and Luiz E. Bermudez $z^{1,3,4}$
${ }^{1,2}$ Laboratory of Bacterial Pathogenesis, Kuzell Institute ${ }^{1}$ and Liposome Research Laboratory ${ }^{2}$, California Pacific Medical Center Research Institute, San Francisco, CA, USA
${ }^{3}$ Department of Biomedical Sciences, College of Veterinary Medicine, Oregon State University, 106 Dryden Hall, Corvallis, OR 97331-4804, USA \\ ${ }^{4}$ Department of Microbiology, College of Sciences, Oregon State University, Corvallis, OR, USA
}

Correspondence
Luiz E. Bermudez
luiz.bermudez@oregonstate.edu

Received 19 February 2003

Accepted 23 May 2003

\section{INTRODUCTION}

Great emphasis has been placed on the study of the interaction between human pathogenic mycobacteria, such as Mycobacterium tuberculosis, Mycobacterium avium, Mycobacterium intracellulare and Mycobacterium leprae, and the human host, but few studies have been directed at the interaction of mycobacteria with the natural environment.

M. avium is an opportunistic pathogen that occurs naturally in the environment but can occasionally cause disease in animals and humans, especially in immunocompromised individuals (Inderlied et al., 1993; Falkinham, 1996). $M$. avium is the main cause of bacteraemia and bacterial disseminated infection in AIDS patients, which is particularly difficult to treat (Wolinsky, 1979). Furthermore, $M$. avium is associated with lung disease in patients with

Abbreviation: GPL, glycopeptidolipid. chronic pulmonary pathology such as emphysema and bronchiectasis (Prince et al., 1989).

A considerable percentage of the population has been shown to react to M. avium antigens (Bermudez et al., 1989), correlating with the finding that M. avium is isolated from environmental sources. More recently, it has been observed that $M$. avium can develop biofilms in urban water systems and on sauna walls (Carson et al., 1978; Falkinham et al., 2001; Schulze-Robbecke \& Fischeder, 1989). M. avium isolates recovered from water systems and natural water sources have the same DNA fingerprint as those isolated from AIDS patients (von Reyn et al., 1994). In addition, since these bacteria are resistant to chlorination (Taylor et al., 2000) and acidic $\mathrm{pH}$ (Bodmer et al., 2000), it can be assumed that they are also common in urban water as planktonic cells, a possibility confirmed in a number of previous studies (Glover et al., 1994; Haas et al., 1983).

Martinez et al. (1999) reported that both Mycobacterium 
smegmatis and $M$. avium can spread on a soft surface by sliding motility. Genetic analysis of M. smegmatis demonstrated that clones with a transposon inserted in transport gene tmtp-C and biosynthetic genes mps do not express sliding motility and do not form biofilms (Recht et al., 2000). These genes encode enzymes involved in glycopeptidolipid (GPL) biosynthesis.

In order to characterize M. avium biofilm and the influence of environmental cues on its formation better, we determined the effect of several conditions on the formation of biofilm.

\section{METHODS}

Strains and growth media. M. avium strains MAC 101, MAC 100, MAC 104, MAC 109, MAC A5 and MAC 5501 were obtained from the blood of AIDS patients. The strains were identified according to serovar by Robert Good (Centers of Disease Control, Atlanta, GA, USA). Culture stocks were established following isolation and bacteria used in the study were obtained from the stock. Mycobacteria were grown aerobically at $37^{\circ} \mathrm{C}$ in Middlebrook $7 \mathrm{H} 9$ medium (Difco) containing $10 \%$ oleic acid, albumin, glucose and catalase (OADC; Hardy Scientific). For growth on solid media, bacteria were plated on 7H10 agar and grown at $37^{\circ} \mathrm{C}$.

Biofilm formation and analysis. Biofilm formation was determined as described previously (O'Toole et al., 2000) by seeding $200 \mu \mathrm{l}$ water, buffer or $7 \mathrm{H} 9$ broth containing $1 \times 10^{7}$ bacteria in a PVC plastic 96 -well microtitre plate (Falcon 3911, Microtest III flexible assay plate; Becton Dickinson). It was assayed by determining the ability of cells to adhere to the wells as reported previously (Limia et al., 2001). Briefly, after inoculation, plates were incubated at room temperature for 14 days and then $25 \mu \mathrm{l}$ of a $1 \%$ crystal violet solution was added to each well (this dye stains the cells but not the PVC). The plates were incubated at room temperature for $15 \mathrm{~min}$, rinsed vigorously four times with water, blotted on paper towels and scored for biofilm formation. The crystal violet was solubilized in $95 \%$ ethanol and the $A_{570}$ was determined as described previously (Limia et al., 2001; O’Toole et al., 2000).

Lipid extraction and TLC. GPLs were isolated as described previously (McNeil et al., 1989) with minor modifications. Briefly, bacterial cultures $(150 \mathrm{ml})$ were grown to turbidity, concentrated by centrifugation in a swinging bucket centrifuge (Sorval RT7) at $1000 \mathrm{~g}$ for $10 \mathrm{~min}$, resuspended in a small volume of water $(10 \mathrm{ml})$ and lyophilized for $2 \mathrm{~h}$. The dry residue was extracted with $50 \mathrm{ml}$ chloroform/methanol $(2: 1)$ and non-solubilized material was removed by centrifugation at $1000 \mathrm{~g}$ for $15 \mathrm{~min}$. The supernatant was carefully removed and the pellet was washed once with a similar volume of solvent. The combined supernatants were dried by rotation evaporation, resuspended in $50 \mathrm{ml}$ chloroform/methanol/ $0 \cdot 2 \mathrm{M} \mathrm{NaOH}(2: 1: 1)$ and incubated at $50{ }^{\circ} \mathrm{C}$ for $30 \mathrm{~min}$ to hydrolyse any ester-containing phospholipids. The incubation mixture was subsequently neutralized with glacial acetic acid. Phase separation was induced by addition of more of both the immiscible aqueous (water, $25 \mathrm{ml}$ ) and organic (2:1 chloroform/methanol; 3-4 $\mathrm{ml}$ ) phases and the mixture was stored in glass vials.

GPLs were analysed by TLC using normal-phase silica gel chromatographic plates (Analtech) and a solvent system composed of chloroform/methanol/water $(30: 8: 1)$. The resolved lipids were developed by iodine staining and subsequently scanned and analysed using the NIH Image software (http://www.nih.gov).

Effect of different conditions on biofilm formation. To determine whether the presence of ions or source of carbon had any effect on biofilm formation, bacteria were incubated in PVC plates in the presence or absence of different concentrations of humic acid, glucose, peptone, $7 \mathrm{H} 9$ broth, $\mathrm{Ca}^{2+}, \mathrm{Zn}^{2+}, \mathrm{Mg}^{2+}$ and $\mathrm{Fe}^{2+}$ and biofilm formation was determined as described above.

Effect of culture supernatant on biofilm formation. In order to examine whether culture supernatant had any effect on biofilm formation, supernatant obtained from $M$. avium culture in 7H9 broth for 7 days in PVC plates was used. Supernatant was filter-sterilized by passing it through a $2 \mu \mathrm{m}$ pore filter. Subsequently, $50 \mu \mathrm{l}$ culture supernatant or $50 \mu \mathrm{l} 7 \mathrm{H} 9$ broth (as a control) was mixed with $100 \mu \mathrm{l}$ water and $1 \times 10^{7}$ bacteria were added. To evaluate the possible role of protein in the formation of $M$. avium biofilm, bacteria were incubated in PVC plates with $4 \mu \mathrm{g}$ amikacin $\mathrm{ml}^{-1}$, a subinhibitory concentration of the antibiotic that inhibits protein synthesis but not bacterial growth (Bermudez et al., 1992).

Resistance of biofilm to disinfectants. Working solutions of biocids were prepared in distilled water and diluted as desired. Biofilm and planktonic bacteria in 96-well PVC plates were challenged for 30 and $60 \mathrm{~min}$, washed with PBS (planktonic bacteria were centrifuged at $10000 \mathrm{~g}$ for $20 \mathrm{~min}$ ), serially diluted and plated onto $7 \mathrm{H} 11$ agar plates. The biocids were used at concentrations of $21 \%$ potassium monochloride, $2 \%$ chloroheximide acetate and $5 \%$ sodium hypochloride (Bardouniotis et al., 2001).

Statistical analysis. Each experiment was repeated at least four times and the results are expressed as means $\pm \mathrm{SD}$. The experimental results were compared with controls and analysed by the non-parametric Mann-Whitney test; $P<0.05$ was considered significant.

\section{RESULTS}

\section{Biofilm formation by $\boldsymbol{M}$. avium strains}

To determine whether the ability to form biofilm differed among several $M$. avium strains, we used four strains obtained from patients and placed them in either water or $7 \mathrm{H} 9$ broth. As shown in Table 1, MAC A5 was associated with greater biofilm formation after 14 days than MAC 109, MAC 101 and MAC 104. MAC 100 was the strain that developed the weakest biofilm. Table 1 also shows that $M$. avium strains formed significantly more biofilm on a PVC surface when incubated in water than in $7 \mathrm{H} 9$ broth and that the ability to establish a biofilm in 7H9 medium did not differ among strains MAC 101, MAC 109 and MAC A5.

\section{Effect of ions on M. avium biofilm formation}

To examine whether different concentrations of ions such as $\mathrm{Mg}^{2+}, \mathrm{Ca}^{2+}, \mathrm{Fe}^{2+}$ and $\mathrm{Zn}^{2+}$, encountered in the environment, could affect the ability of $M$. avium strains to form biofilm, we used strain MAC A5 in water in the presence of a range of concentrations of ions. Table 2 shows that the presence of $\mathrm{Ca}^{2+}, \mathrm{Mg}^{2+}$ or $\mathrm{Zn}^{2+}$ was associated with increased biofilm formation compared with growth in water alone and that the amount of biofilm formed in the presence of concentrations of $\mathrm{Ca}^{2+}, \mathrm{Mg}^{2+}$ and $\mathrm{Zn}^{2+}$ from $0 \cdot 1$ to $10 \mu \mathrm{M}$ did not vary significantly.

\section{Effect of the source of carbon on biofilm formation}

Because M. avium in the environment is exposed to different 
Table 1. Biofilm formation in water and 7H9 medium

Bacteria were incubated in different media in a PVC 96-well plate for 14 days. Biofilm formation was evaluated at days $1,4,7$ and 14 as described in Methods. Values are means \pm SD $A_{570}$ readings from three experiments (multiplied by 1000).

\begin{tabular}{|c|c|c|c|c|c|}
\hline Strain & Medium & Day 1 & Day 4 & Day 7 & Day 14 \\
\hline \multirow[t]{2}{*}{ MAC 100} & Water & $42 \pm 3$ & $96 \pm 38$ & $216 \pm 54^{\star}$ & $436 \pm 45^{\star}$ \\
\hline & $7 \mathrm{H} 9$ & $44 \pm 8$ & $68 \pm 11$ & $87 \pm 10$ & $124 \pm 28$ \\
\hline \multirow[t]{2}{*}{ MAC 101} & Water & $46 \pm 4$ & $180 \pm 41^{*}$ & $424 \pm 26^{*}$ & $691 \pm 25^{\star}$ \\
\hline & $7 \mathrm{H} 9$ & $47 \pm 6$ & $86 \pm 11$ & $210 \pm 18$ & $307 \pm 15$ \\
\hline \multirow[t]{2}{*}{ MAC 109} & Water & $41 \pm 2$ & $197 \pm 34^{*}$ & $501 \pm 39^{*}$ & $696 \pm 38^{*}$ \\
\hline & $7 \mathrm{H} 9$ & $43 \pm 2$ & $96 \pm 14$ & $256 \pm 50$ & $299 \pm 10$ \\
\hline \multirow[t]{2}{*}{ MAC 104} & Water & $45 \pm 2$ & $152 \pm 33^{*}$ & $387 \pm 19^{*}$ & $665 \pm 36^{*}$ \\
\hline & $7 \mathrm{H} 9$ & $52 \pm 10$ & $82 \pm 8$ & $181 \pm 26$ & $273 \pm 44$ \\
\hline \multirow[t]{2}{*}{ MAC A5 } & Water & $42 \pm 5$ & $191 \pm 24^{\star}$ & $491 \pm 30^{*}$ & $869 \pm 30^{*}$ \\
\hline & 7H9 & $43 \pm 5$ & $94 \pm 14$ & $243 \pm 41$ & $316 \pm 17$ \\
\hline
\end{tabular}

${ }^{\star}$ Statistically significantly different $(P<0 \cdot 05)$ compared with biofilm formed in $7 \mathrm{H} 9$ medium at the same time-point.

\section{Table 2. Effects of ions on M. avium biofilm formation}

Strain MAC A5 was incubated in water with or without ions in a PVC 96-well plate and biofilm formation was measured as described in Methods. Values are means $\pm \mathrm{SD} A_{570}$ readings from three experiments (multiplied by 1000).

\begin{tabular}{|lllc|}
\hline Ion & Day 1 & Day 7 & Day 14 \\
\hline Water & $50 \pm 4$ & $502 \pm 74$ & $933 \pm 53$ \\
$\mathrm{Mg}^{2+}$ & & & \\
$0 \cdot 1 \mu \mathrm{M}$ & $50 \pm 5$ & $652 \pm 13$ & $1604 \pm 45^{\star}$ \\
$1 \mu \mathrm{M}$ & $43 \pm 8$ & $731 \pm 51^{\star}$ & $1629 \pm 40^{\star}$ \\
$10 \mu \mathrm{M}$ & $49 \pm 3$ & $789 \pm 37^{\star}$ & $1632 \pm 43^{\star}$ \\
$\mathrm{Ca}^{2+}$ & & & \\
$0 \cdot 1 \mu \mathrm{M}$ & $47 \pm 6$ & $632 \pm 36$ & $1566 \pm 37^{\star}$ \\
$1 \mu \mathrm{M}$ & $53 \pm 2$ & $717 \pm 47^{\star}$ & $1548 \pm 49^{\star}$ \\
$10 \mu \mathrm{M}$ & $46 \pm 6$ & $763 \pm 24^{\star}$ & $1607 \pm 15^{\star}$ \\
$\mathrm{Fe}^{2+}$ & & & \\
$0 \cdot 1 \mu \mathrm{M}$ & $53 \pm 5$ & $516 \pm 30$ & $842 \pm 19$ \\
$1 \mu \mathrm{M}$ & $43 \pm 7$ & $531 \pm 49$ & $856 \pm 23$ \\
$10 \mu \mathrm{M}$ & $47 \pm 6$ & $547 \pm 28$ & $851 \pm 54$ \\
$\mathrm{Zn}^{2+}$ & & & \\
$0 \cdot 1 \mu \mathrm{M}$ & $44 \pm 3$ & $561 \pm 21$ & $1202 \pm 27^{\star}$ \\
$1 \mu \mathrm{M}$ & $48 \pm 2$ & $640 \pm 37^{\star}$ & $1311 \pm 41^{\star}$ \\
$10 \mu \mathrm{M}$ & $51 \pm 4$ & $684 \pm 24^{\star}$ & $1320 \pm 46^{\star}$ \\
\hline
\end{tabular}

${ }^{*}$ Statistically significantly different $(P<0 \cdot 05)$ compared with water control.

sources of carbon that may differ from the sources available in the host (lung airways, for example), we examined whether exposure to a number of sources of carbon would have an effect on the establishment of a biofilm. Table 3 shows that M. avium in water formed more stable biofilm in the presence of glucose and peptone, but not in the presence of humic acid. Since different growth could explain the results obtained, we quantified $M$. avium on the three different media (three carbon sources), as described in Methods. No significant difference was observed in the number of bacteria (data not shown).

\section{Analysis of GPLs of M. avium strains}

A direct correlation has been made between the presence of GPLs, a class of amphiphilic molecules isolated in the outermost layers of the cell wall, and the ability of cells to translocate over a surface and the ability to form biofilm (Martinez et al., 1999). To extend our analysis, we extracted the lipid from M. avium strains and performed TLC. Fig. 1 shows that MAC 101, MAC 104 and MAC A5 had significant amounts of polar GPL, while almost no polar GPL was detected in MAC 100. A semiquantitative analysis of the GPLs within the same culture was determined by integration of the iodine-stained GPLs using the NIH Image software (Table 4).

\section{Effect of culture supernatant on biofilm formation}

The ability of bacteria to form biofilms has been linked to quorum sensing, or the ability of micro-organisms to send messages to other members of the colony (Greenberg, 1998). Therefore, we decided to evaluate whether MAC A5 supernatant (7H9 broth of a culture) had any effect on biofilm formation in water. Table 5 shows that, in the presence of supernatant, there was a significant increase in the ability to form biofilm, compared with controls. Because the effect of supernatant suggests the presence of bacterium-derived molecules that affect biofilm formation, we placed MAC A5 in water in the presence of $4 \mu \mathrm{g}$ amikacin $\mathrm{ml}^{-1}$, a subinhibitory concentration shown to inhibit protein synthesis (Bermudez et al., 1997). Biofilm formation was reduced significantly (Table 5). 
Table 3. Effect of carbon source on M. avium biofilm formation

Strain MAC A5 was incubated in the presence or absence of different carbon sources and biofilm formation was determined as described in Methods. Values are means \pm SD $A_{570}$ readings from three experiments (multiplied by 1000).

\begin{tabular}{|lccc|}
\hline Carbon source & Day 1 & Day 7 & Day 14 \\
\hline Water (none) & $34 \pm 3$ & $385 \pm 46$ & $714 \pm 55$ \\
Glucose (2\%) & $28 \pm 6$ & $853 \pm 56^{*}$ & $1681 \pm 104^{\star}$ \\
Peptone (1\%) & $30 \pm 4$ & $1513 \pm 177^{\star}$ & $2310 \pm 168^{\star}$ \\
Humic acid $\left(0 \cdot 05 \mathrm{mg} \mathrm{ml}^{-1}\right)$ & $29 \pm 4$ & $209 \pm 27$ & $667 \pm 41$ \\
\hline
\end{tabular}

*Statistically significantly different $(P<0 \cdot 05)$ compared with water control.

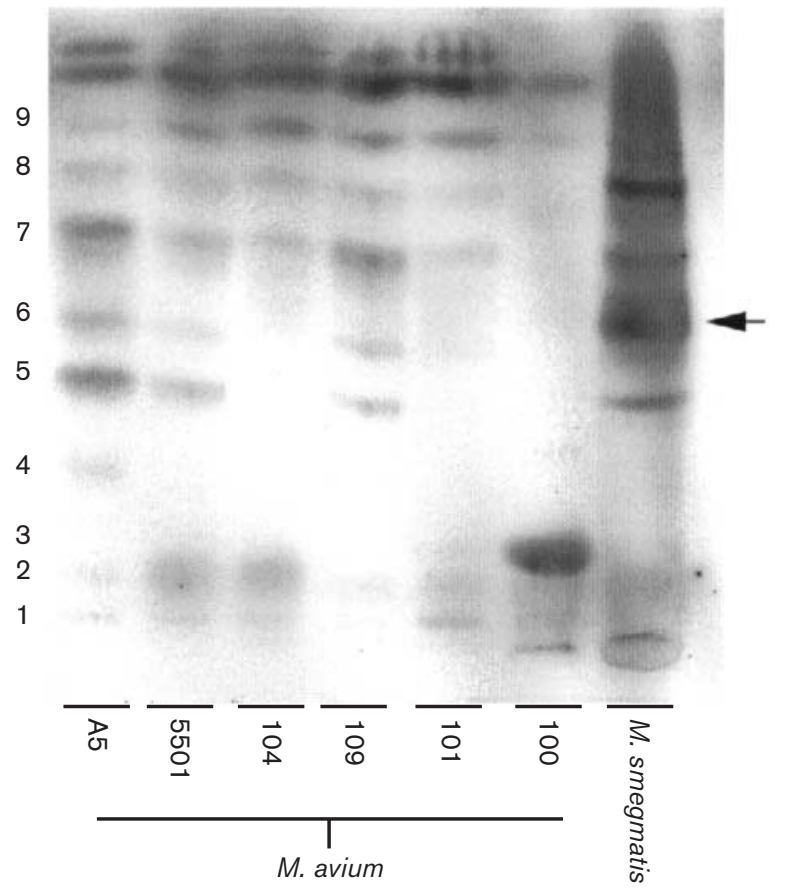

Fig. 1. TLC of GPLs isolated from $M$. smegmatis or $M$. avium strains MAC A5, MAC 5501, MAC 104, MAC 109, MAC 111 and MAC 100. GPLs were isolated from bacterial cultures as described in Methods. Results of a semiquantitative analysis of the GPLs are given in Table 4.

\section{Resistance to biocids}

Planktonic bacteria $\left(10^{7}\right)$ and biofilm were incubated with biocids for 30 and $60 \mathrm{~min}$, and the percentage of viable bacteria was then determined. As shown in Table 6, all the biocids were significantly more active against planktonic bacteria than against the biofilm form.

\section{DISCUSSION}

M. avium is a human pathogen that causes pulmonary disease and disseminated infection (Inderlied et al., 1993; Falkinham, 1996) in both immunosuppressed and immunocompetent individuals. M. avium is an environmental organism encountered in water and soil and, therefore, most of the human and animal population comes into contact with the bacterium during their lifetime. In the environment, M. avium can form biofilms, as studies have demonstrated (Carson et al., 1978; Falkinham et al., 2001; Martinez et al., 1999; Schulze-Robbecke \& Fischeder, 1989). The bacterium has been found in municipal water systems (Falkinham et al., 2001) as well as on the walls of sauna houses in Finland (Schulze-Robbecke \& Fischeder, 1989).

In this study, we observed that the ability of M. avium to form biofilm was strain-dependent under the conditions used. This was not surprising, given the heterogeneity of the M. avium strains. Among the strains tested, MAC 101, MAC 104, MAC 109 and MAC A5 are virulent in the mouse model, while MAC 100 is attenuated (Bermudez et al., 1992). Based on this observation, it was tempting to correlate the ability to form biofilm with the virulence of the strain in the host, since MAC 100, the most attenuated strain in mice following intravenous or oral challenge, does not form film very effectively. However, we are not able to reach a definitive conclusion on this point. The results obtained in this study confirmed previous findings, that biofilm formation is more effective when bacteria are placed in water than in $7 \mathrm{H} 9$ broth medium (Limia et al., 2001). Past observation has shown that, in water, but not in 7H9 broth, M. avium upregulates the expression of $\sec A$, which suggests that biofilm formation may be associated with protein secretion (Limia et al., 2001).

Martinez et al. (1999) suggested that sliding motility was associated with the ability to form biofilm. We have confirmed this original observation (data not shown) and extended the finding to include a number of clinical isolates. Work by Martinez et al. (1999) also demonstrated that there was a close relationship between the capacity of a strain for sliding motility and biofilm formation and the amount of GPL. GPL is believed to form a hydrophobic film over the hydrophilic agar surface, reducing interaction between the bacterium and the agar and allowing spreading. Although this corresponds to a phenotype in vitro, the relevance of sliding motility in the environment is currently unknown. It is possible that GPLs are not the only bacterial component responsible for sliding motility, since $M$. avium and M. smegmatis GPLs show significant variations, while both have sliding motility on agar.

The quality and quantity of nutrients, ions and several other substances present in the environment are known to influence bacterial behaviour and would certainly be expected to have a regulatory role in the formation of biofilm. For example, Pseudomonas aeruginosa uses organic acids as a source of carbon to form biofilm (O'Toole et al., 2000). In addition, Kirschner et al. (1992) showed that M. avium grows better in water rich in zinc and humic acid. Our work demonstrates that $M$. avium establishes more stable biofilms in the presence of $\mathrm{Ca}^{2+}, \mathrm{Mg}^{2+}$ and $\mathrm{Zn}^{2+}$, but not $\mathrm{Fe}^{2+}$. In 
Table 4. Semiquantitative analysis of GPLs

Iodine-stained GPL bands (numbered as shown in Fig. 1) were integrated using the NIH Image software. Values are percentages of total integrated densities of the desired GPLs within a single lane. NI, Not included.

\begin{tabular}{|c|c|c|c|c|c|c|c|c|}
\hline \multirow[t]{2}{*}{ Band } & \multirow[t]{2}{*}{$R_{\mathrm{f}}$} & \multicolumn{6}{|c|}{ M. avium } & \multirow[t]{2}{*}{ M. smegmatis } \\
\hline & & MAC A5 & MAC 5501 & MAC 104 & MAC 109 & MAC 101 & MAC 100 & \\
\hline 1 & $0 \cdot 14$ & $5 \cdot 88$ & $6 \cdot 29$ & $12 \cdot 82$ & $0 \cdot 58$ & $10 \cdot 86$ & $7 \cdot 98$ & $0 \cdot 38$ \\
\hline 2 & $0 \cdot 21$ & $2 \cdot 33$ & $19 \cdot 42$ & $48 \cdot 94$ & $4 \cdot 49$ & $4 \cdot 75$ & $10 \cdot 03$ & $4 \cdot 44$ \\
\hline 3 & $0 \cdot 23$ & $0 \cdot 00$ & $0 \cdot 00$ & $0 \cdot 00$ & $0 \cdot 00$ & $1 \cdot 27$ & $77 \cdot 49$ & $0 \cdot 05$ \\
\hline 4 & $0 \cdot 35$ & $2 \cdot 42$ & $0 \cdot 84$ & $0 \cdot 00$ & $0 \cdot 00$ & $0 \cdot 00$ & $0 \cdot 25$ & $0 \cdot 13$ \\
\hline 5 & $0 \cdot 48$ & $32 \cdot 59$ & $27 \cdot 47$ & $1 \cdot 52$ & $14 \cdot 13$ & $0 \cdot 00$ & $0 \cdot 00$ & $2 \cdot 89$ \\
\hline 6 & $0 \cdot 56$ & $6 \cdot 17$ & $3 \cdot 01$ & $0 \cdot 72$ & $9 \cdot 18$ & $6 \cdot 56$ & $0 \cdot 00$ & $43 \cdot 07$ \\
\hline 7 & $0 \cdot 69$ & $37 \cdot 43$ & $26 \cdot 95$ & $7 \cdot 16$ & $43 \cdot 25$ & $23 \cdot 45$ & $0 \cdot 00$ & $9 \cdot 72$ \\
\hline 8 & $0 \cdot 78$ & $11 \cdot 03$ & $6 \cdot 61$ & $5 \cdot 08$ & $10 \cdot 12$ & $17 \cdot 07$ & $1 \cdot 05$ & $39 \cdot 31$ \\
\hline 9 & $0 \cdot 85$ & $2 \cdot 14$ & $9 \cdot 41$ & $23 \cdot 76$ & $18 \cdot 26$ & $36 \cdot 03$ & $3 \cdot 20$ & NI \\
\hline
\end{tabular}

Table 5. Effect of culture supernatant and inhibition of protein synthesis on M. avium biofilm formation

Culture supernatant was obtained as described in Methods. Strain MAC A5 was incubated in the media shown and biofilm formation was determined as outlined in Methods. Values are means \pm SD $A_{570}$ readings from three experiments (multiplied by 1000).

\begin{tabular}{|lll|}
\hline Medium & Day 1 & Day 7 \\
\hline Water & $56 \pm 8$ & $426 \pm 12$ \\
Water+supernatant $(50 \mu \mathrm{l})$ & $52 \pm 4$ & $673 \pm 46^{*}$ \\
Water+7H9 $(50 \mu \mathrm{l})$ & $50 \pm 2$ & $301 \pm 26$ \\
Water+amikacin $\left(4 \mu \mathrm{g} \mathrm{ml}^{-1}\right) \dagger$ & $47 \pm 4$ & $186 \pm 11^{*}$ \\
7H9 $(50 \mu \mathrm{l})$ & $44 \pm 6$ & $346 \pm 15$ \\
\hline
\end{tabular}

${ }^{\star}$ Statistically significantly different $(P<0.05)$ compared with water control.

$\dagger$ MIC of amikacin for strain MAC A5 is $12 \mu \mathrm{g} \mathrm{ml}^{-1}$. addition, glucose and peptone were sources of carbon in medium associated with increased biofilm formation. $\mathrm{Hu}-$ mic acid, however, was associated with less biofilm formation. The differences between our results and those of Kirschner et al. (1992) might result from the strains used or the contents of the medium. It is possible that, because humic acid chelates cations, including $\mathrm{Ca}^{2+}$ and $\mathrm{Mg}^{2+}$, it decreased the number of divalent cations available for efficient biofilm formation. Since M. avium has been shown to establish biofilms in the water systems of urban areas, as well as on the walls of public saunas, one wonders whether those conditions linked with biofilms in vitro are present in the environments in which $M$. avium biofilms have been identified. Of note is the fact that increased amounts of zinc have been found in urban water systems (Kirschner et al., 1992). In addition, we believe that other sources of carbon besides those tested can be associated with M. avium biofilm formation. As an extension of this work, it would be interesting to investigate the conditions that exist in the

Table 6. Bactericidal effect of biocids against $M$. avium

Inocula of approx. $10^{7}$ planktonic bacteria and bacteria in biofilm (sessile) were incubated with several biocids. At the times shown, the biocid was removed by washing and the bacterial load was determined by plating into 7H100 agar plates. Values are means \pm SD c.f.u. $\mathrm{ml}^{-1}$.

\begin{tabular}{|llrc|}
\hline Biocid & Form & 30 min & 1 h \\
\hline None & Planktonic & $1 \pm 0 \cdot 4 \times 10^{7}$ & $1 \cdot 3 \pm 0 \cdot 2 \times 10^{7}$ \\
& Biofilm & $3 \cdot 2 \pm 0 \cdot 5 \times 10^{8}$ & $3 \cdot 3 \pm 0 \cdot 4 \times 10^{8}$ \\
Sodium hypochloride $(0 \cdot 5 \%)$ & Planktonic & $8 \cdot 1 \pm 0 \cdot 5 \times 10^{6}$ & $7 \cdot 4 \pm 0 \cdot 4 \times 10^{6}$ \\
& Biofilm & $2 \cdot 9 \pm 0 \cdot 4 \times 10^{7}$ & $1 \cdot 9 \pm 0 \cdot 3 \times 10^{7}$ \\
Potassium monopersulfate (21\%) & Planktonic & $2 \cdot 4 \pm 0 \cdot 2 \times 10^{6}$ & $5 \cdot 1 \pm 0 \cdot 5 \times 10^{5}$ \\
& Biofilm & $8 \cdot 7 \pm 0 \cdot 3 \times 10^{6 *}$ & $9 \cdot 3 \pm 0 \cdot 2 \times 10^{6 *}$ \\
Chloroheximide acetate (2\%) & Planktonic & $7 \cdot 9 \pm 0 \cdot 4 \times 10^{5}$ & $8 \cdot 3 \pm 0 \cdot 6 \times 10^{4}$ \\
& Biofilm & $6 \cdot 9 \pm 0 \cdot 4 \times 10^{6 *}$ & $7 \cdot 7 \pm 0 \cdot 3 \times 10^{6 *}$ \\
\hline
\end{tabular}

${ }^{*}$ Statistically significantly different $(P<0 \cdot 05)$ compared with the effect on planktonic bacteria. 
airways of patients with bronchiectasis, for instance, and to establish whether those conditions could facilitate biofilm formation by $M$. avium strains.

A connection between biofilm formation and quorum sensing has been established for a number of bacteria (Greenberg, 1998). Our results suggest that similar mechanisms may have a role in the formation of M. avium biofilm. The facts that culture supernatant led to a significant increase in the ability to establish biofilm and that inhibition of protein synthesis suppressed biofilm formation potentially indicate that a protein-mediated signal(s) present in the supernatant stimulates biofilm formation.

The role of biofilm in M. avium pathogenesis is unknown. Because M. avium colonizes the respiratory tract of patients with chronic pulmonary disease and the initial colonization usually evolves to an infection that is difficult to eradicate, it is plausible that biofilm formation might have a substantial role in the maintenance of the mucosal infection. The observation that $M$. avium in biofilm form is significantly more protected from the action of biocids than are bacteria in planktonic form supports the idea that the phenotype is adopted for protection against the harmful conditions of the environment. Further work is necessary to establish this association.

\section{ACKNOWLEDGEMENTS}

This work was supported by the Fund for Arthritis and Infectious Diseases of the Kuzell Institute and by grant no. 1-AI-25140 of the National Institute of Allergy and Infectious Diseases. We thank Dr Joseph Falkinham, III, for providing M. avium strains A5 and 5501 and for advice on this work. We also thank Karen Allen for the preparation of the manuscript.

\section{REFERENCES}

Bardouniotis, E., Huddleston, W., Ceri, H. \& Olson, M. E. (2001). Characterization of biofilm growth and biocide susceptibility testing of Mycobacterium phlei using the MBEC assay system. FEMS Microbiol Lett 203, 263-267.

Bermudez, L. E., Wu, M., Enkel, H. \& Young, L. S. (1989). Naturally occurring antibodies against Mycobacterium avium complex. Ann Clin Lab Sci 19, 435-443.

Bermudez, L. E., Petrofsky, M., Kolonoski, P. \& Young, L. S. (1992). An animal model of Mycobacterium avium complex disseminated infection after colonization of the intestinal tract. J Infect Dis 165, 75-79.

Bermudez, L. E., Petrofsky, M. \& Goodman, J. (1997). Exposure to low oxygen tension and increased osmolarity enhance the ability of Mycobacterium avium to enter intestinal epithelial (HT-29) cells. Infect Immun 65, 3768-3773.

Bodmer, T., Miltner, E. \& Bermudez, L. E. (2000). Mycobacterium avium resists exposure to the acidic conditions of the stomach. FEMS Microbiol Lett 182, 45-49.

Carson, L. A., Petersen, N. J., Favero, M. S. \& Aguero, S. M. (1978).
Growth characteristics of atypical mycobacteria in water and their comparative resistance to disinfectants. Appl Environ Microbiol 36, 839-846.

Falkinham, J. O., III (1996). Epidemiology of infection by nontuberculous mycobacteria. Clin Microbiol Rev 9, 177-215.

Falkinham, J. O., III, Norton, C. D. \& LeChevallier, M. W. (2001). Factors influencing numbers of Mycobacterium avium, Mycobacterium intracellulare, and other mycobacteria in drinking water distribution systems. Appl Environ Microbiol 67, 1225-1231.

Glover, N., Hultzman, A., Aronson, T. \& 8 other authors (1994). Isolation and identification of Mycobacterium avium complex recovered from Los Angeles potable water, a possible source of infection in AIDS patients. Int J Environ Health Res 4, 63-72.

Greenberg, P. E. (1998). Quorum sensing in gram-negative bacteria. ASM News 63, 371-377.

Haas, C. N., Meyer, M. A. \& Paller, M. S. (1983). The ecology of acid-fast organisms in water supply, treatment and distribution system. $J$ Am Water Work Assoc 75, 139-144.

Inderlied, C. B., Kemper, C. A. \& Bermudez, L. E. (1993). The Mycobacterium avium complex. Clin Microbiol Rev 6, 266-310.

Kirschner, R. A., Jr, Parker, B. C. \& Falkinham, J. O., III (1992). Epidemiology of infection by nontuberculous mycobacteria. Mycobacterium avium, Mycobacterium intracellulare, and Mycobacterium scrofulaceum in acid, brown-water swamps of the southeastern United States and their association with environmental variables. Am Rev Respir Dis 145, 271-275.

Limia, A., Sangari, F. J., Wagner, D. \& Bermudez, L. E. (2001). Characterization and expression of secA in Mycobacterium avium. FEMS Microbiol Lett 197, 151-157.

Martinez, A., Torello, S. \& Kolter, R. (1999). Sliding motility in mycobacteria. J Bacteriol 181, 7331-7338.

McNeil, M., Chatterjee, D., Hunter, S. W. \& Brennan, P. J. (1989). Mycobacterial glycolipids: isolation, structures, antigenicity, and synthesis of neoantigens. Methods Enzymol 179, 215-242.

O’Toole, G. A., Gibbs, K. A., Hager, P. W., Phibbs, P. V., Jr \& Kolter, R. (2000). The global carbon metabolism regulator $\mathrm{Crc}$ is a component of a signal transduction pathway required for biofilm development by Pseudomonas aeruginosa. J Bacteriol 182, 425-431.

Prince, D. S., Peterson, D. D., Steiner, R. M., Gottlieb, J. E., Scott, R., Israel, H. L., Figueroa, W. G. \& Fish, J. E. (1989). Infection with Mycobacterium avium complex in patients without predisposing conditions. N Engl J Med 321, 863-868.

Recht, J., Martinez, A., Torello, S. \& Kolter, R. (2000). Genetic analysis of sliding motility in Mycobacterium smegmatis. J Bacteriol 182, $4348-4351$.

Schulze-Robbecke, R. \& Fischeder, R. (1989). Mycobacteria in biofilms. Zentbl Hyg Umweltmed 188, 385-390.

Taylor, R. H., Falkinham, J. O., III, Norton, C. D. \& LeChevallier, M. W. (2000). Chlorine, chloramine, chlorine dioxide, and ozone susceptibility of Mycobacterium avium. Appl Environ Microbiol 66, 1702-1705.

von Reyn, C. F., Maslow, J. N., Barber, T. W., Falkinham, J. O., III \& Arbeit, R. D. (1994). Persistent colonisation of potable water as a source of Mycobacterium avium infection in AIDS. Lancet 343, 1137-1141.

Wolinsky, E. (1979). Nontuberculous mycobacteria and associated diseases. Am Rev Respir Dis 119, 107-159. 